\title{
Michael Guest*
}

\author{
Faculty of Medicine \\ University of Miyazaki, Japan \\ michael@med.miyazaki-u.ac.jp
}

\section{THE CLINICAL CASE PRESENTATION AS A NARRATIVE: FORM AND PRACTICE}

\section{Abstract}

This paper examines an underrepresented genre of spoken clinical discourse - the clinical case presentation. Since little generic research into this peer-to-peer speech event has been conducted and also due to the fact that case presentations are often neglected by English for Medical Purposes (EMP) teachers, particularly those without backgrounds or experience in medicine, the author will explain both how and why case presentations are constructed and performed, particularly by clinicians who practice in non-English clinical milieus. This study is based upon a number of observations carried out at 10 clinical university hospitals in nonEnglish normative parts of Asia, involving observations of a total of 36 distinct clinical case presentations performed in 10 different clinical departments. These observations were further supplemented by structured interviews with senior clinicians, instructors, training program designers, and presenters. One of the prominent features noted of expert presenters is that their presentations tend to extend well beyond the mere conveyance of clinical data and serve to express a narrative - the story of the patient's case - which produces a more holistic impact upon the audience. Features of narrative that are incorporated into this speech event will be discussed, followed by a discussion as to how the teaching and learning of case presentations might best be carried out in EMP classes.

\section{Key words}

English for medical purposes, clinical English, narrative, speech event, case presentation, spoken English.

\footnotetext{
* Corresponding address: Michael Guest, University of Miyazaki, 5200 Kihara, Oaza, Kiyotake-cho, Miyazaki Pref. 889-1692, Japan.
} 


\section{INTRODUCTION AND BACKGROUND}

One of the challenges faced by teachers of ESP working in a content field in which they have no expertise or professional background is the difficulty of developing an awareness of various 'insider' speech events and the related means of managing professional discourses.

A decade ago, I had already been teaching English for Medical Purposes (EMP) in the Faculty of Medicine at a university in Japan for 10 years when I stumbled upon an entirely new (for me) EMP speech event, one that is considered to be a fundamental measure of a clinician's professional communication skill, one that is almost universally performed, but also one that had been hitherto hidden from me. I am referring to clinical oral case presentations (hereafter abbreviated to 'CPs'), situated speech events in which healthcare professionals formally present interesting or exemplar clinical cases to their peers (as well as superiors and/or students), almost always within a specific clinical department. It is such situated speech events that have been described as a central principle of genre knowledge (Berkenkotter \& Huckin, 1995) with speech events within a particular discourse community not being entirely fixed but still allowing for systematic interactions (Fairclough, 1992).

Attending and performing CPs is considered a fundamental part of the continuing skill development of clinicians, particularly in terms of aiding the development of novice clinician and medical student reasoning and/or problemsolving skills, which medical practitioners will use throughout their careers. Thus, explicit attention from EMP teachers in order to teach these skills is warranted (Edwards, Brannan, Burgess, Plauche, \& Marier, 1987). Interestingly, Schryer, Lingard, Spafford, and Garwood (2003) report that many clinicians could not actually recall any explicit learning of how to perform CPs at all even though they "considered it to be an important part of their daily function as physicians" (2003: 71). CPs have further been described as "exercises in self-presentation which serve as a vehicle for professional socialization" and as a "linguistic ritual in which physicians learn and enact fundamental beliefs and values of the medical world" (Anspach, 1988: 357). CPs serve as prime examples of what Bazerman (1994) describes as speech genres representing social constructs that serve to regulate speech behavior within a specific discourse community.

This paper's scope does not include case reports, written versions of oral case presentations, nor does it deal with bedside case presentations, which are educational training sessions for small groups of medical students and an instructor held in the wards or in seminar classrooms, which has been estimated to represent $25 \%$ of all CPs. There has been a move away from the bedside practice of CPs into lecture halls (Gonzalo, Masters, Simons, \& Chuang, 2009), reflecting an apparent preference of clinicians (Wang-Cheng, 1989). The focus of this paper is, instead, the formalized, situated, peer-to-peer CP speech event, which is performed 
for peer edification or evaluating the clinical problem-solving skills of residents and novice physicians.

Distinguishing these two CP types is crucial. The dynamics of oral CPs performed by novices while being evaluated by experts or superiors directly affects the structure of the performance, due to qualities such as frequent interruptions by evaluators during novice CPs (Lingard, Schryer, Garwood, \& Spafford, 2003; Weinholz, 1983). While instructors and evaluators may be inclined to view CPs primarily as opportunities for the shared construction of knowledge, Lingard, Garwood, Schryer, and Spafford (2003) note that expert feedback was often not incorporated into the $\mathrm{CP}$, suggesting that CPs were being treated by evaluators and novice presenters at cross-purposes. Therefore, she argues, CPs should not merely be the mechanical rendering of a data template but include multiple, flexible iterations.

Schryer et al. (2003) emphasize the tension between the formal, textual structure of CPs, the role it plays in the socialization of novices into a professional 'habitus', and the role of agency that the presenter brings in terms of making strategic choices for CP presentation to better allow for flow. The structure of a CP is standardized in order to serve as a type of gate-keeper for the discourse community, determining allowable contributions and the socialization into a professional 'habitus' or identity, but the agency of the presenter also requires 'strategic choices' which might offer resistance to the textual norms of the speech event. The agency of the CP thus becomes negotiated in performance via these strategic choices and the utilization of problem-solving skills.

From the late 1990s until 2009, I had been focusing my EMP teaching almost exclusively upon healthcare worker-patient interactions, particularly the intricacies of effective history taking, as well as the development of academic skills, such as conference presentations, leading academic discussions, and research writing.

Clinician-patient history taking is a particularly common teaching/learning area in EMP classes, partially, no doubt, because all EMP instructors, regardless of whether they have academic backgrounds in medicine or not, have experienced being a patient and would thus likely be at least somewhat comfortable with teaching such encounters. And academic skills are obviously required for physicians in order to actively partake in the international medical discourse community and thus present themselves as being self-evident departure points of pedagogical worth. But case presentations? What were they?

For a field outsider, such as myself, CPs represented the unknown 'other', the private world of specialist spoken discourses. I was aware, thanks to TV medical dramas, that healthcare professionals often gave data-laced case briefings to one another when handing over patient duties or in emergency cases but was largely unaware that an entire category of medical discourse had escaped my teaching attention. 
I had developed a sturdy reputation as a teacher of academic presentation skills for non-native English speaking physicians when I was asked by a faculty member from a prestigious university to perform a workshop on delivering CPs in English. Initially, I assumed that such speech events referred only to that element of an academic presentation in which an exemplar case is inserted for illustrative purposes. I was soon to find out how little I actually knew.

After several subsequent years of observation, research, and teaching, I have since become aware that CPs are in fact core clinical speech events, not only due to their near-universality but also because they epitomize clinical critical thinking processes. Moreover, for the non-native English speaker, mastery of CP performance can mark membership within the international medical discourse community. As such, I will argue in this paper that CPs present much of learning value to EMP students, not so much in that learners might come to master this single speech event in English, but because of the formative role CPs can play in the nascent clinician's overall cognitive development, particularly in terms of extending the notion of 'conveying data' to that of 'narrating a patient's story'. As such, the potential 'dryness' of reporting clinical data now includes consideration of the 'other' - the patients, and their stories.

In line with the scant notice that CPs appear to get from EMP teachers or within medical English textbooks, there is also a relative paucity of academic literature dealing with the subject. While much has been written about speech events within professional/academic domains, and the generic structures of, and subsequent rhetorical 'moves' therein, many clinician-clinician speech events appear to have undergone relatively little detailed analysis (Atkinson, 1995).

Significant among the few extant studies are references to the unfortunate depersonalization of the language and the omission of the agent in many CPs, negating the import of the subjective experience of the patient (Anspach, 1988). CP language, particularly that of the agentless passive treats "the presentation of the entire case history from the point of view of an omniscient, anonymous narrator" which results in negating the patient's perspective from the history of present illness section, which "loudly signals their insignificance in medical care" (Donnelly, 1997: 1046). In short, as Chan (2015: 3) argues, "[t]he OCP is not merely a structured piece of text type whose surface patterns can be acquired as a set of rules".

As clinicians become increasingly aware of deploying empathy in patient interviews, particularly by framing such encounters primarily as 'story-telling' events (Warmington, 2019), so too has the impetus to increase the deployment of the patient's perspective, subjectivity, and clinician's doubts and struggles within the CP. Skelly, Rosenbaum, Barlow, and Priebe (2019) contrast the dynamic interactions that emerge between clinicians and patients with the traditionally detached character of the $\mathrm{CP}$, with a subsequent call for $\mathrm{CP}$ sessions to be more cognizant of communicative cues that emerge during clinician-patient interviews. Much of this recent movement towards emphasizing a more narrative approach to 
CPs emanates from Bakhtin's reaction against 'theoretism' in analyzing dialogues; the underlying assumption that events are somehow best understood when presented in accordance with pre-existing rules and structures, negating the import of intimacy and immediacy ("We cannot understand the world of events from within the theoretical world. One must start with the act itself, not with its theoretical transcription" [Bakhtin, 1986 as cited in Morson \& Emerson, 1990: 50]).

Lingard et al. (2003b) note the presenter's agency particularly reflected in the management of unreliable or uncertain CP items. Aversion to elements of uncertainty helps to foster an ideology of uncertainty reduction that is pervasive in medicine (Brashers, 2001). Such reported dislike of uncertainty among clinicians can manifest itself as a more dogmatic clinical approach (Timmermans \& Angell, 2001). And yet the element of uncertainty is integral to the story, the narrative of the case, much in the same way that uncertainty makes a suspense drama that much more compelling.

The essential symbiotic relationship between the knowledge of macrotextual CP form and the development of clinical narratives is pursued by $\mathrm{Lu}$ and Corbett (2012), while the further inclusion of extra-textual, socio-pragmatic, and socio-cognitive elements of professional discourse is emphasized by Bhatia (2004). The latter two sources in particular influenced the approach I used when gathering and analyzing CP data. Chan (2015) further advocates analyzing the rhetorical and discursive features of expert CP performance, as opposed to utilizing a methodological basis based on expert opinions about CPs, which she suggests will better serve as models for novice non-native English speaking clinicians. This approach, too, informed my own study.

In this paper, I will briefly outline what case presentations are and how they work, the parameters of the observations carried out, focusing upon how CPs serve as a means of drawing non-native English speakers into the wider Englishspeaking community. However, rather than creating a mere template of generic 'moves' I will spend the bulk of this paper discussing how CPs best operate as a type of narrative, with their myriad variations, quirks, anomalies, and, particularly, the unique functions CPs take on when performed in non-native English speaking settings.

\section{SETTINGS AND METHODS OF OBSERVATION}

\subsection{Settings}

In order to observe how English CPs are managed and performed in non-native English speaking settings I visited several Universities and affiliated hospitals. The number of CP observations (see Table 1) is presented according to locale 
(total $=36$ ) as well as the number of interviews with presenters/practitioners (total=26).

\begin{tabular}{|l|l|c|c|}
\hline UNIVERSITY & COUNTRY & NUMBER OF OBSERVATIONS & NUMBER OF INTERVIEWS \\
\hline Thammasat Univ. & Thailand & 12 & 3 \\
\hline Chiang Mai Univ. & Thailand & 4 & 3 \\
\hline Prince of Songkla Univ. & Thailand & 3 & 2 \\
\hline Brawijaya Univ. & Indonesia & 4 & 3 \\
\hline Hong Bang Intl Univ. & Vietnam & 2 & 2 \\
\hline Can Tho Univ. & Vietnam & 3 & 3 \\
\hline Hanoi Medical Univ. & Vietnam & 5 & 3 \\
\hline $\begin{array}{l}\text { Yangon Univ. of } \\
\text { Medicine }\end{array}$ & Myanmar & 0 & 2 \\
\hline Cheng Kung Univ. & Taiwan (ROC) & 3 & 2 \\
\hline University of Miyazaki & Japan & 0 & $\mathbf{2 6}$ \\
\hline TOTAL & & $\mathbf{3 6}$ & \\
\hline
\end{tabular}

Table 1. Locations of CP observations

\subsection{Methods of observation}

$\mathrm{CP}$ observations were carried out in the following departments, with a minimum of two observations within each specialty field: Endocrinology, Anaesthesiology, Obstetrics-Gynecology, Pediatrics, Respiratory, Family Medicine, Ophthalmology, Surgery, Nursing, and Community Medicine.

\begin{tabular}{|l|l|}
\hline EXTERNAL CATEGORIES & INTERNAL (GENERIC) CATEGORIES \\
\hline Date & Opening framework/management of background \\
\hline Location & Order of data \\
\hline Clinical Department & Interpretations/Expansion \\
\hline $\begin{array}{l}\text { Text/Presenter's position/role/status } \\
\text { speech) }\end{array}$ & Adherence to standardized CP forms \\
\hline \multirow{5}{*}{ Nother than } & Notable Exclusions/Omissions \\
\hline & Special emphases \\
\cline { 2 - 2 } & Novel or local acronyms/abbreviations \\
\cline { 2 - 2 } & Academic formulaic phrases \\
\cline { 2 - 2 } & Notable interactive/narrative/transitional features \\
\cline { 2 - 2 } & Closing framework \\
\cline { 2 - 2 } & Discussion/Follow up points of note \\
\cline { 2 - 2 } & $\begin{array}{l}\text { Take home message and/or Investigator's additional } \\
\text { comments }\end{array}$ \\
\hline
\end{tabular}

Table 2. Author's case presentation observation checklist 
Gaining access in order to observe English CPs was a major factor in determining the choice of both institution and specialist department. In all cases, permission for observation was granted via a clinical or academic contact within the institution who sought out departmental permission, or through the Research Ethics Committee of the institution, which required more formalized approval.

Observation involved note-taking and, on only five occasions, was aided by audio recording (video recording was refused). The notes were codified according to the categories shown in Table 2.

The selection of these categories was based upon two factors. One involved the deployment of Grounded Theory (Strauss \& Corbin, 1998), in which distinct categories gradually emerged and expanded from the phenomena I was observing. This meant that in regard to early observations, categories had to be refined (usually added) retrospectively. The second factor was a loose adherence to both Hymes's (1974) SPEAKING model outlining the external categories of analyzing situated speech events, further informed by Bhatia's (1993) notion of 'interdiscursivity', which augments the above with a wider socio-cognitive framework.

\subsection{Interviews}

Interviews regarding the parameters, roles, and function of English CPs within specific or regional institutions were conducted with department heads, course designers, senior physicians, trainee physicians, junior physicians, EMP teachers, and upper-grade (5-6 $6^{\text {th }}$ year) students. Of these, only on three occasions was I given permission to record. The remainder were carried out by notetaking. The pre-established questions posed during the interviews generally followed the basic formula displayed below. However, variations and extensions upon this basic formula were quite common due to the vagaries of real-time communication, making the interviews in effect semi-structured.

1. Do you perform clinical case presentations in English or in your indigenous/local language? If both, what are the percentages of each?

2. In what situations do doctors carry out English case presentations at your medical/educational institution as opposed to using the local/mother tongue?

3. What elements are typically included in a case presentation?

4. Is there any formal style or template used for doing case presentations?

5. When do students usually learn how to do case presentations, whether in L1 or English?

6. How are these taught to students and/or practiced by them?

7. What aspects of the model (a rougher version of the synopsis found below) are you familiar or unfamiliar with?

8. Do you have any wish or need to upgrade education in this particular area? If so, what is needed ad how might it be carried out? 


\subsection{General synopsis of the CP speech event}

Based on these observations, as well as existing, ready-made CP forms, templates, and outlines made freely available ${ }^{1}$ or readily obtained through a Google search, ${ }^{2}$ a synopsis of the macro-textual 'moves' or categories within a CP may be constructed as shown in Table 3. Items and/or section lesser known to the layperson have been appended with a brief description/explanation:

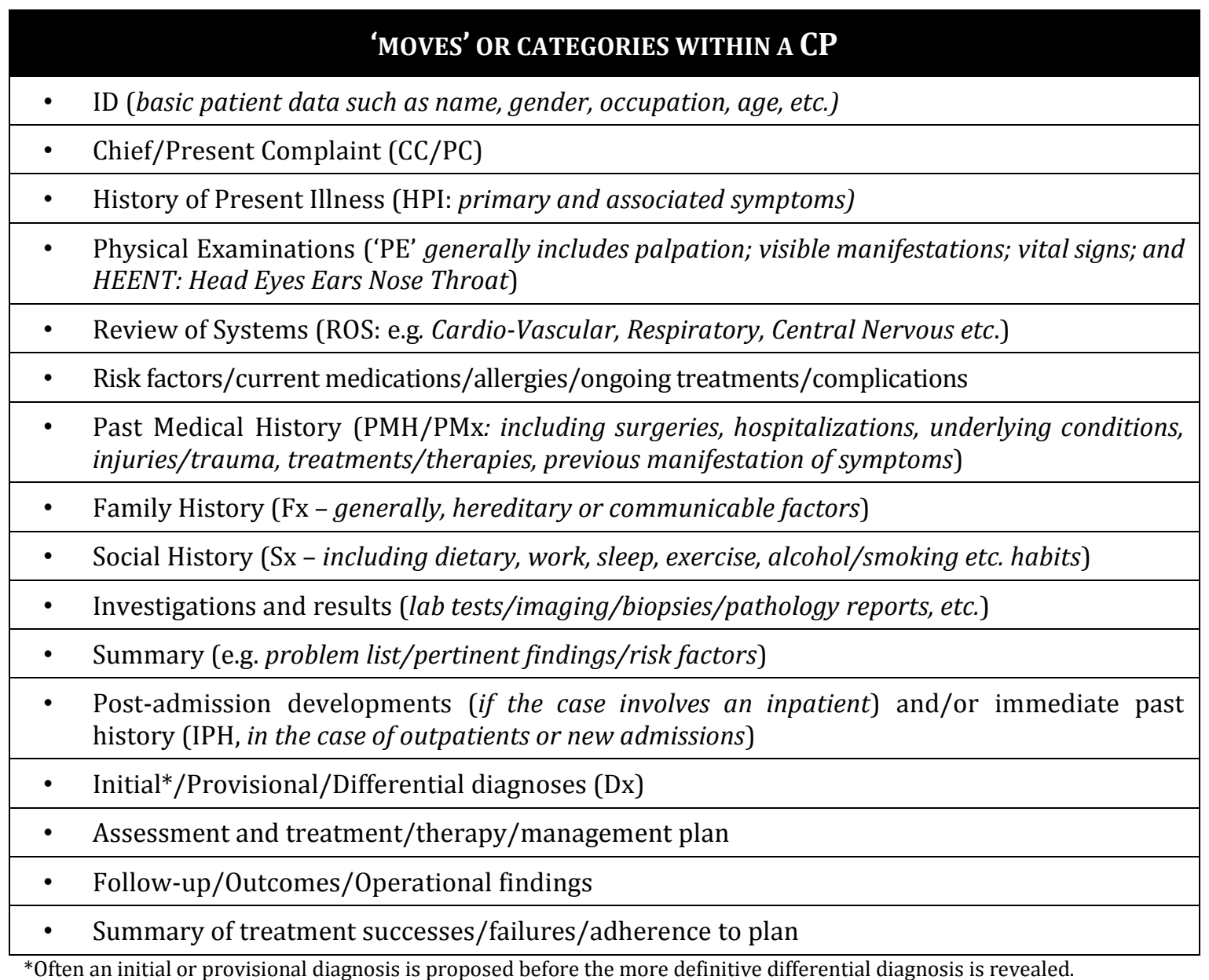

Table 3. Synopsis of Clinical Case Presentation Categories or 'Moves'

It must be emphasized from the outset that an effective CP is not merely the sum of the specific clinical data contained in the above synopsis but, rather, should be the

\footnotetext{
${ }^{1}$ http://www.fortunejournals.com/archives-of-clinical-and-medical-case-reports-home-acmcr.php ${ }^{2}$ https://www.google.com/search?q=medical+case+presentation+template\&sxsrf=ALeKk01nOWziFV ov2Cr-xTslXg_0ABhfMg:1589859170509\&source=lnms\&sa=X\&ved=0ahUKEwjRk-

f4_r7pAhVBPnAKHSdOCiAQ_AUICSgA\&biw=1920\&bih=967\&dpr=1
} 
'story' of the patient's particular case (Anspach, 1988; Donnelly, 1997; Schryer et al., 2003; Warmington, 2019), which is why CP performances are usually prefaced as being 'interesting' cases or model 'exemplar' cases. Schryer, Lingard, and Spafford (2005) speak of students and attending physicians accessing a range of strategies as they co-constructed the event.

One of Schryer et al.'s (2005) student subjects explicitly refers to developing a case presentation as trying to make a movie out of a patient. The student further explained: "It just sort of helps you to organize your thoughts better [...] to make a story of what might seem like sort of a chaotic bunch of events", adding, however, that, "without a structure, it's really hard to make sense of anything" (2005: 62). In other words, the formal macro-structure of the speech event needs to be augmented by an element of story-telling - a narrative.

In short, the reporting of case data alone must not be conflated with the telling of the case story, as the latter includes the human elements of decisionmaking, the analysis of data (the process of critical thinking), confounding and complicating factors, unwieldy or unusual findings, 'subjective' patient responses, the vagaries of idiosyncratic situational factors, sudden interventions, and numerous types of other incongruous case minutiae. In a $\mathrm{CP}$, the process through which a patient comes to reveal data and a clinical decision is made and carried out is at least as important as the product: the accumulation of data, or final clinical outcome.

\section{EXTRA-TEXTUAL FEATURES OF CLINICAL CASE PRESENTATIONS}

For the purposes of this paper, less space will be used upon examining the structure of the synoptic speech event itself and more upon the features of $\mathrm{CP}$ management and delivery plus the environmental, socio-cultural, and idiosyncratic parameters that imbue the event with the marks of a narrative. These features will be addressed by posing a series of questions, each followed by an answer or explanation. The recurring themes within each question and subsequent answer/explanation will attempt to highlight those qualities that provide CPs with its essential narrative form.

The first five questions will deal with extra-textual features of CPs as performed by non-native English speakers and are based on the clinical observations locations listed earlier. 


\subsection{When and where do CPs take place?}

Every one of the CPs observed took place either within a university Faculty of Medicine conference or classroom, or within affiliated hospital departmental conference rooms. The vast majority were held early in the morning, starting between 7 or 8 a.m., lasting one to two hours, before most clinicians begin their working shifts or students/instructors start their daily schedules, in order to maximize attendance. CPs were, in every case observed, specialist departmental affairs being held anywhere from three times a week to once a month. CPs were a standard, regularly scheduled, highly situated event within every department of every university-affiliated hospital/Faculty of Medicine that I visited. Just under $50 \%$ of those departments whose CPs I observed required that clinicians perform the CP in English on every occasion. For the remaining 50+\%, English CPs were performed an average of once per month with the remainder performed in the local language.

\subsection{Who performs CPs and why?}

Generally, younger clinicians were asked to present, both individually and in pairs or groups of three. Indeed, it might be said that performing in-house CPs constitutes a rite-of-passage for residents and/or trainees. These CPs tend to consist of three types: a) 'Interesting cases', performed largely for the edification of departmental peers, b) Research reports, as a part of the process of preparing the speaker for a research publication and/or an international conference presentation, and c) Evaluated presentations, a required part of the training process of younger doctors with critical input provided by senior clinicians acting as advisors and/or evaluators. CPs are also widely used as training sessions for residents with $\mathrm{CP}$ performances regularly making up an integral part of the required trainee learning curriculum. For special instructional purposes a senior clinician may also serve as the presenter ( 9 of the 36 total CPs observed were performed by senior clinicians).

Upper-grade medical students were also regularly required to carry out CPs in English as a part of their clinical clerkship programs. However, these usually took place in standard seminar classrooms within the Faculty of Medicine facilities or in the hospital wards, with only an instructor (clinical, not language) and a small group of upper-grade peers (typically 4-8) partaking.

Determining the type of presenter/presentation has a profound effect upon the management of the CP narrative as both the purpose and prevailing power relationships significantly altered the relationship between presenter(s) and audience/participants (Schryer et al., 2003). For example, 'interesting case' CPs tended to be more peer-to-peer speech events such that there was little or no power differential between audience and speaker. In most such cases, a greater air 
of informality prevailed with a corresponding greater number of impromptu exchanges between the presenter(s) and the audience. In many 'interesting case' $\mathrm{CPs}$, the presenters advanced the $\mathrm{CP}$ by asking the participants to elicit the significant patient history data or they presented alternatives and options regarding diagnoses or management/treatment suggestions that were discussed openly. As such, the formally rigid 'moves' of the CP synopsis became somewhat blurred.

Conversely, the presenter(s) of interesting cases tended to very much emphasize those elements of the case that provided it with its points of interest or uniqueness. To a large degree, this meant omitting certain standard categories of a $\mathrm{CP}$ in order to highlight particular features considered to be intriguing or of research/practice significance to their peers.

Such highlighting often required the use of explicit discourse markers employed to direct the narrative in a manner that made it more comprehensible to the listener. Common examples included:

(1) So, how/why did we make that decision/diagnosis?

(2) In summary then, the most significant factors/results/findings were...

(3) So, based on the data/labs/imaging/investigations/physical examination, we...

Younger non-native English-speaking clinicians occasionally struggled in this regard, uncertain of the tools and forms commonly used to mark movements distinct from the more formulaic moves used in a $\mathrm{CP}$, in which the only the section or category name was stated prior to commentary.

In two cases observed, presenters tasked with presenting interesting cases could find no case of their own that met requirements and so instead opted to present interesting or significant new research findings taken from academic journals or online sources for both the edification of their peers and extended open discussion.

\subsection{Who is the CP 'audience'?}

Any clinician in a particular department is encouraged (and occasionally required) to attend the scheduled CPs. Clinical clerkship upperclassmen medical students are also often required to attend these. Most ominously (for novice presenters), the audience may include senior adjudicators who are present to evaluate the performance of the speaker. In the case of clinical clerkship CPs performed by upper-grade students, there is no audience as the endeavor is treated as a collaborative learning exercise between the instructor and student team members. In such cases, all members are expected to participate while observing and listening. 
The role or function of the audience, and indeed whether attendees may be more accurately described as participants, alters depending upon whether the CP is a peer-to-peer session or an evaluated interaction. In the case of a peer-to-peer session, audience members are generally required to become active participants wherein the presenters might elicit clinical moves or suggestions from the participants, solicit requests for particular data, or ask open questions to instigate group discussion. In the latter type of sessions, the bulk of the audience is silent and passive while the adjudicators wait until the completion of the CP before they respond with further questions and/or critical comments. Given the more passive role of the audience in such cases, it becomes incumbent upon the presenter to deliver the $\mathrm{CP}$ in a more standardized or codified manner, adhering closely to the template form.

\subsection{How, and why, does the form and/or content of a CP vary?}

In order to answer this question, I will discuss the multimodal nature of the CP speech event first.

While the majority of CPs revolve around the modes of PowerPoint slides accompanied by the presenter's speech, other media are often actively employed. These include handouts (usually containing copies of authentic medical imaging and reports, such as pathology reports, investigative findings, CT scans, various other clinical documents, statistical analyses, etc.), live image models generated on the computer using specialized software, and, occasionally, transcripts of spoken interactions with patient or allied health professionals.

The more visual data that is presented, the less detailed or explicit the verbal content of the CP tends to become. 'As you can see...' or 'As the --- indicates...' are stock phrases used when referring to accompanying images or documentation, since the attending clinicians will be able to interpret the images or data without explicit explanation. However, if and when medical students are present in the audience there is a greater tendency to explain the image or data more thoroughly.

In about $50 \%$ of the cases involving evaluation and adjudication, an established, usually local, CP template was used by the speaker and check-listed by the adjudicators (and was often distributed to all members of the audience). The utilization of such a template tended to reduce the possibilities of narrative extension, forcing the speaking into a more formulaic conveying of the case. However, such templates, it must be remembered, also offer a scaffold for lessthan-proficient English speakers. Those unsure of their linguistic abilities would naturally find conforming to a set script more comforting, particularly in such a profoundly situated academic/professional speech event.

In such cases, more nuanced element of the patient's story emerged later in the follow-up Q\&A sessions when adjudicators probed the speakers about significant data, the rationale used behind the clinician's decision-making 
processes, or the choice of differential diagnosis or management/treatment. As such, the narrative element was appended largely retrospectively to more formalized CP texts.

Textual choices of inclusion, exclusion, emphasis or minimizing of data were largely affected by the vagaries of the particular case and, most prominently, based on the clinical department in question. For example, quite naturally, anesthesiologists concentrate more on treatment and operative findings, with much less concern for the history of present illness (HPI) section. Obstetricians tend to focus upon immediate past history (IPH) and post-admission developments, particularly when concerned with perinatal cases. Respiratory physicians tend to favor family and social history (FH/SH) as well as physical examinations (PE) and the review of systems (ROS). The longer the presenter had been working in the particular department the more succinct the CPs became parts of the template that had little bearing on the speaker/audience's specialty were routinely ignored. The exception to this 'rule' was, once again, trainee and young clinicians who tended to follow the comprehensive 'safe' mode of the formal template.

One notable feature of $\mathrm{CP}$ management was that when the features that might normally be pertinent to a specific department were not deemed sufficiently pertinent in a particular patient's case, the presenter usually made the explicit point of stating 'insignificant' as opposed to simply omitting the feature altogether.

\subsection{What qualities separated expert presenters from novices?}

It was the management of a $\mathrm{CP}$ as being a type of narrative that often separated the veteran and senior physicians observed, as well as those in teaching/adjudicating roles, from the less experienced trainees, students, and junior physicians. The former generally presented their cases as narratives, the 'story' of the case, while those in training or subordinate positions tended to focus more upon conveying the more 'objective' case data, often presented as a series of discrete items. Expert practitioners were also more likely to omit or minimize certain categories if they felt that these impeded the conveyance of the narrative whereas less experienced presenters tended to be comprehensive, often at the expense of establishing a more holistic comprehension among the audience/participants.

\subsection{Why are CPs performed in English in non-native English clinical settings?}

Surely the local language would be the most effective means of communicating. And yet, in over half of the locales visited, CPs were required to be performed in English, including the follow up discussion and/or Q\&A. In the accompanying 
interviews numerous responses were given to this question, each of which is discussed below.

a. Preparatory reasons: The presenter was preparing for an upcoming international presentation, currently involved in international collaborative research, or was soon to be carrying out research or practice abroad. English CPs provided a practice or proving ground.

b. Inclusivity reasons: If the audience/participants included non-locals (beyond myself). About $40 \%$ of the institutions visited had foreign medical students or healthcare workers who were more proficient in English than they were in the local language.

c. Expediency reasons: In almost all of the locales visited, textbooks are written - and thus taught - in English, with very little clinical research of note being carried out in the local language. In many cases, clinical documentation was also required to be carried out in English. This meant that in terms of clinical content, participants were often more comfortable interacting in English (with some notable exceptions, to be described later).

The qualities described above underscore the degree to which English is utilized as a medical lingua franca in these otherwise non-native English speaking locations. Several interviewees explained that professional workplace discourse among speakers of a common L1 was already peppered with English terms and phrases, many of which do not translate readily into the local tongue. Therefore, it was said to be a natural step to carry out at least some clinical functions in English without causing too much of a cognitive shift (although, interestingly, this did not seem to be the case in Japan).

d. English as manifesting 'professionalism': Perhaps the most interesting reason given for performing CPs in English was the widely expressed notion that English imbued the sessions with a sense of sobriety, and, with that, gave the event an added air of professionalism.

As one interviewee put it, English was preferred because "[i]f we perform CPs in (the local language) we tend to get sloppy and be less well organized as we know that we can easily reformulate and recover to express what we want to say. But using English forces us to be more careful about how we arrange and order the contents, and how to connect the information in a logical - and clinically correct manner." In other words, more explicit concern for the structure of the narrative function increases when the CP is carried out in English, the clinicians' second language. 
As such, it appears that the Vygotskian (1978) notion of 'languaging' - that the shift from cognition to linguistic expression serves to enable greater clarity of thought - holds sway. As the interviewees above stated, when negotiating the process of developing a meaningful, cohesive CP in an L2, cognition must be engaged in a more deliberate and careful manner than it would normally be. In this sense, it may be even argued that performing CPs, or any similar structured professional speech event, in a second language might have a positive washback effect upon the presenter's cognitive grasp of the field or domain they are discussing.

\section{NOTEWORTHY TEXTUAL FEATURES IN NON-NATIVE ENGLISH CPS}

In this section, I will discuss some of the salient textual features that highlight the narrative functions of the CPs. These are taken from a combination of recordings and notes.

\subsection{Formulaic academic phrases vs. 'general' English}

Particularly in evidence was the manner in which shards and chunks of formulaic academic phrases weaved their way into the narrative, serving not only as a cohesive device but also to situate the narrative. Some examples of these would include:

(4) The presence of $X$ was indicated by... (in the labs section)

(5) SH was significant for high alcohol intake but was otherwise unremarkable (in social history)

Such forms are marked by their professional/academic register but would not be considered to be specialist terminology per se. These academic formulaic expressions are closer in tenor to the written mode and, as such, would rarely be used in insider-outsider speech. However, in CPs, they served to underline the formalized nature of the speech event. Perhaps unsurprisingly, there was a tendency for upper-grade students and new trainee clinicians to not be aware of the appropriate academic register and instead deploy more casual expressions:

(6) Because $X$ is there, it means there's more chance that it's because of Y.

In some cases, these were repaired by instructors or seniors by offering the more appropriate professional register as a response: 
(7) So, the presence of $\mathrm{X}$ increases the likelihood of $\mathrm{Y}$ being the cause.

Interestingly however, once scripts moved away from the more established template territory, forms more typical of non-native English speakers or English as a lingua franca users emerged. This occurred among almost all presenters. For example:

(8) In that time we don't know if it is infect or not infect.

Interestingly, most presenters displayed greater proficiency in using clinical terminology and formulaic expressions than when using more general spoken forms, particularly when giving unscripted commentary.

The degree of separation between such 'general' constructions and established formulaic academic phrases in terms of register could be quite jarring. However, despite such constructions not meeting canonical notions of formalized English 'correctness', these utterances rarely, if ever, appeared to have any negative impact upon comprehension of the participants/audience, if measured in terms of the paucity of repair comments from evaluators or peers or request for semantic, as opposed to clinical, clarification.

\subsection{Abbreviations and acronyms in speech}

There was a notable habit among novices to read data, including the abbreviated items, exactly as indicated on the document:

(9) PET scan revealed RUL mass of $2 \times 1.5 \mathrm{~cm}, \mathrm{w} /$ suspected $\mathrm{rt}$ hilar and rt interlobar nodal metastasis + possible bilateral adrenal metastasis.

In the above example, only 'rt' to 'right' and 'w/' to 'with' were adapted for speech. Senior and/or veteran presenters however tended to decorate such utterances with evaluative extra-textual commentary:

(10) So, as we expected, the (investigation/lab) was (numerical data) which is consistent with the standard. But, at the same time, there was (contraindications), so we decided we better to investigate why was this happening.

\subsection{Code-switching}

On occasion, code-switching occurred during English CPs. L1 interventions were most readily apparent during discussion/Q\&A sessions and were utilized mainly as a form of repair, generally in cases where pragmatic nuances or specific data 
regarding the English question or comment had not been adequately grasped by one or more of the participants. Once clarified, the interactions generally reverted back to English. In some cases, rare terms or expressions in English were glossed in L1 during the body of the CP. L1 idiomatic expressions that did not have an adequate matching English translation were also often appended to the English text. These were, however, exclusively non-clinical items.

One notable use of code-switching involved requests for repair, particularly regarding clarification of the chronology of clinical events, particularly when the speaker failed to clearly invoke the perfective aspect (particularly has/had versus was/did), glossing over temporal inflections of English verbs. Hung, Chen, and Tsai (2012) have reported similar problems regarding the performance of English CPs in Taiwan.

\section{FURTHER ELEMENTS OF NARRATIVE WITHIN THE CP TEXT}

One way in which many veteran clinicians distinguished their CPs from those of novices was the manner in which they imbued their raw data with storytelling features. Most evaluators interviewed in Schryer et al.'s (2003) study agreed that one of the salient reasons that certain CPs performances impressed them was that "the presenter had a better command of the organizational structure of case presentations" (2003: 74). Most of Schryer et al.'s (2003) students also mentioned that one of the most salient differences between novice and expert CPs was that the more expert cases were characterized by 'flow' and attention to organization.

In my own study, while the novices, as might be expected, tended to follow the scripted template closely, their more experienced counterparts used explicit discourse signals, expanded upon sections deemed worthy of particular notice, and made more explicit efforts to tie the diagnosis and outcomes to rationales underlying the decision-making process.

For some presenters, this type of narrative extension became prominent even in the patient ID section. While many novices tended towards stating age and gender only before moving on to the HPI, some presenters gave names, nationalities, marital status, occupation, and, perhaps most significantly, how much of a frequent attender - and for what purposes - the patient is/was. Relevant biographical information was appended to the basic data.

Another notable feature observed in the CPs of veteran speakers was the manner in which the narrative element was realized through a subtle shift from ellipsis to fully-formed grammatical constructions when a significant item was conveyed. The following example

(11) Blood pressure 105 over 60, pulse normal, RS, HEENT nothing abnormal detected... 
was delivered with articles and verbs elided, typical of the manner in which standardized data is communicated between professionals. However, the presenter then shifted to full syntactical forms:

(12) ... but the WBC count was unusually high, which suggested...

marking a shift in the narrative to a significant piece of information which affected the telling of the decision-making story.

Extended commentary that imbued the CP with the force of a narrative was also particularly noteworthy during case summaries. Most compelling were those CPs in which the presenter conveyed an element of clinical confusion, error/failure, or initial indecision. Such CPs had the uptake of a complex mystery. For example, one case involved a pseudo-pregnancy, in which manifestations of pregnancy appear in the patient in the physical examination but are unconfirmed by lab and imaging tests. Although pregnancy could be ruled out quickly, the process by which the attending doctors weighed the physical manifestations against the patient's psychological status and past medical history and thereby could establish if the manifestations were primarily genito-urinary related or rooted in the patient's mental condition was as enthralling as a medical drama.

Such narratives highlight the human roles of both doctors and patients in the clinical process, as opposed to the mere reporting of management and treatment decisions simply as a product of cumulative data.

\section{EMP TEACHING AND TRAINING SUGGESTIONS FOR CPS}

It is perhaps notable that in only two of the locales visited (Cheng Kung University, Taiwan, and Chiang Mai University, Thailand) were students explicitly taught how to perform a CP. And in no location was it stated or admitted that the teaching/learning of narrative features of CPs might be a preferred or necessary approach. And yet several trainees and students not only performed the CPs proficiently, but chose to include elements of narrative.

One of the reasons that CPs were not explicitly taught in many locales was a widely expressed belief that the traditional clinical focus upon medical students and trainee clinicians to generate an accurate diagnosis should naturally guide speakers into providing the pertinent background data. Moreover, it was expressed that exposure to CPs performed by more senior colleagues would, by force of expert example, generate awareness among students and trainees as to the generic structure of a CP.

However, in the CPs of novices or students, this appears to have led to an inordinate emphasis upon the centrality of the diagnosis as opposed to the broader story of the case and, particularly, that of the patient. This could also explain why, generally speaking, novice presenters tended to avoid narrative elements and kept 
mostly to the data-based script, with the focus upon generating and rationalizing a diagnosis, management plan, or treatment.

It is at this pedagogical point that language teachers may effectively encourage the development of CP skills that go beyond the data culminating in a diagnosis and produce a narrative that has a deeper impact upon the audience/participants. So then, how might this be effectively conducted in the EMP classroom?

With lower-grade medical students, who may not yet be proficient either in English skills or clinical knowledge, it makes good sense to introduce CPs while initially adhering to a limited and standardized CP synopsis/template. Edwards et al. (1987) recommend that the teaching and learning of CPs be divided into three phases: (1) reporting and organising patient information (clinical data); (2) analysing and synthesising (problem list and differential diagnosis); and (3) managing the case (diagnostic and therapeutic plan). Further, four teaching principles can facilitate students' learning of the three phrases; these are (1) communicating objectives and expectations; (2) directing attention; (3) expanding the case; and (4) giving feedback.

However, once the various categories or 'moves' are understood by learners, proceeding in a section-by-section fashion, the next step would involve learners supplying their own clinical content (research may be necessary in order to produce accurate or realistic case scenarios), such that they can develop a sense of 'ownership' of the discourse and a subsequent responsibility for conveying the case effectively - creating the sense that this 'patient's story' is generated by, and belongs to, them.

To do this effectively, once the basic clinical data has been established, the onus is upon both learners and the instructor to consider what the clinical priorities are, what specific data demands extended commentary or special emphasis, and what data is significant or not, as well as what can be safely omitted. The gradual expansion of a nascent CP section-by-section allows learners not only to feel comfortable with both the clinical content and the appropriate mode of English expression, but more readily helps to make apparent which items are most pertinent and which items are not. Continual pair, trio, or small group work in which the emerging CPs are conveyed to peers also allows for continuous feedback regarding accuracy of data, relevance, and the cohesive relationship between the different data categories.

It is only when the learners feel comfortable that their CP makes fundamental clinical and linguistic sense that the added ingredients of the narrative should be considered. Having new listeners summarize their peers' cases, highlighting the most pertinent data therein, and asking for relevant data that may have been ignored helps presenters to round their presentation into a more listener-friendly form. At this point the instructor can also suggest discourse signals and prosodic markers that serve to bring the case more to life.

The final stage of production would be to have medical students view the CP from a patient's perspective (even though patients are not normally privy to CPs). 
In particular, the question as to what data would be most relevant to the patient needs to be addressed. While clinicians are naturally prone to focus upon the generating of diagnoses and suggesting management and treatments, patients often want to know how the diagnosis, management, or treatment will affect their lives on a daily basis. Will they be able to play the piano again? Does the treatment require time off from work? What are the chances of any residual or lasting effect? At this point, the learners might also consider to what degree patients (or their families) might be required to know or understand the clinical details.

CPs can be assessed in performance in front of a small group, followed by both peer and instructor Q\&A and, later, commentary (written and/or spoken). The use of multimodal presentation forms should be encouraged, which would allow instructors to assess the presentation of the data and/or images in written or graphic modes and to ask questions that would illuminate aspects of the case that are beyond the instructor's level of clinical knowledge.

By focusing on the explicit teaching of CPs in this manner, by the completion of the course or project, it can be hoped that learners will have advanced from merely reporting synoptic moves to having produced and performed a full narrative, a CP that tells the story of a patient, not merely a 'case', and one that looks not only to accumulated data of the past but also to a more holistic view of the present and future.

\section{SUMMARY}

Clinical case presentations are core, situated speech events regularly practiced among medical practitioners worldwide. Even in non-English speaking milieus, English is often used as the lingua franca of the performance. CPs vary according to type (evaluative, informative, instructional), the make-up of audience/participants, and the type of clinical department or specialty. The purpose of carrying out CPs in English in non-native English settings is also varied, but the rationale of using a second language as a means of ensuring care in constructing the clinical narrative, as a type of cognitive facilitator, is particularly significant. And while there may be said to be a loose template of standard CP categories, suggesting a series of preestablished speech event 'moves', in reality these steps are often exploited, adjusted, omitted, or expanded upon by practitioners in order to establish a more cohesive narrative. This is a skill that is utilized by experts within the medical discourse community and thus is one that should be taught to residents, trainees, and upper-grade medical students as well. Not only, then, should CPs be explicitly learned in EMP classrooms but instructors should also endeavor to heighten learner awareness of the wider interactive, communicative scope of this speech event. Most importantly, the movement away from data-only summarizations towards a more interpretive telling of the patient's story humanizes the encounter 
in that both the performance of a CP and the wider goals of holistic health care are treated in accord.

[Paper submitted 14 Jan 2020]

[Revised version received 28 May 2020]

[Revised version accepted for publication 16 Sep 2020]

\section{Acknowledgements}

The author would like to thank Dr. Prakitpunthu Tomtitchong of Thammasat University, Thailand, for helping to facilitate many of the visits and observations described in the paper, and the Faculty of Medicine at the University of Miyazaki, Japan, for allowing me to take a research sabbatical to carry out this study. Funding was enabled through Grant-in-aid for Scientific Research ('Kaken-hi') number 17K02931, courtesy of the Japanese Ministry of Education, Culture, Sports, Science, and Technology (MEXT).

\section{References}

Anspach, R. (1988). Notes on the sociology of medical discourse: The language of case presentation. Journal of Health and Social Behavior, 29(4), 357-375.

Atkinson, P. (1995). Medical talk and medical work. London: Sage Publications Ltd.

Bazerman, C. (1994). Systems of genres and the enactment of social intentions. In A. Freedman, \& P. Medway (Eds.), Genre and the new rhetoric (pp. 79-101). London: Taylor \& Francis.

Berkenkotter, C., \& Huckin, T. (1995). Genre knowledge in disciplinary communication. Hillsdale, NJ: Lawrence Erlbaum.

Bhatia, V. K. (1993). Analyzing genre: Language use in professional settings. London/New York: Longman.

Bhatia, V. K. (2004). Worlds of written discourse: A genre-based view. New York: A\&C Black.

Brashers, D. E. (2001). Communication and uncertainty management. Journal of Communication, 51(3), 477-497. https://doi.org/10.1111/j.1460-2466.2001.tb02892.x

Chan, M. Y. (2015). The oral case presentation: Toward a performance-based rhetorical model for teaching and learning. Medical Education Online, 20(1). https://doi.org/10.3402/meo.v20.28565

Donnelly, W. J. (1997). The language of medical case histories. Annals of Internal Medicine, 127(11), 1045-1048. https://doi.org/10.7326/0003-4819-127-11-199712010-00035

Edwards, J. C., Brannan, J. R., Burgess, L., Plauche, W. C., \& Marier, R. L. (1987). Case presentation format and clinical reasoning: A strategy for teaching medical students. Medical Teacher, 9(3), 285-292. https://doi.org/10.3109/01421598709034790

Fairclough, N. (1992). Discourse and social change. London: Polity.

Gonzalo, J. D., Masters, P. A., Simons, R. J., \& Chuang, C. H. (2009). Attending rounds and bedside case presentations: Medical student and medicine resident experiences and attitudes. Teaching and Learning in Medicine, 21(2), 105-110. https://doi.org/10.1080/10401330902791156

Hung, H., Chen, P. C., \& Tsai, J. J. (2012). Rhetorical structure and linguistic features of case presentations in case reports in Taiwanese and international medical journals. Journal of English for Academic Purposes, 11(3), 220-228. https://doi.org/10.1016/j.jeap.2012.04.004 
Hymes, D. H. (1974). Foundations in sociolinguistics: An ethnographic approach. Philadelphia: University of Pennsylvania Press.

Lingard, L., Garwood, K., Schryer, C. F., \& Spafford, M. M. (2003). A certain art of uncertainty: Case presentation and the development of professional identity. Social Science \& Medicine, 56(3), 603-616. https://doi.org/10.1016/S0277-9536(02)00057-6

Lingard, L., Schryer, C. F., Garwood, K., \& Spafford, M. M. (2003). 'Talking the talk': School and workplace genre tension in clerkship case presentations. Medical Education, 37(7), 612-620. https://doi.org/10.1046/j.1365-2923.2003.01553.x

Lu, P. Y., \& Corbett, J. (2012). English in medical education. Bristol, UK: Multilingual Matters.

Morson, G. S., \& Emerson, C. (1990). Mikhail Bakhtin: Creation of a prosaics. Stanford: Stanford University Press.

Schryer, C. F., Lingard, L., \& Spafford, M. M. (2005). Techne or artful science and the genre of case presentations in healthcare settings. Communication Monographs, 72(2), 234-260. https://doi.org/10.1080/03637750500120485

Schryer, C. F., Lingard, L., Spafford, M. M., \& Garwood, K. (2003). Structure and agency in medical case presentations. In C. Bazerman, \& R. D. Russell (Eds.), Writing selves/writing societies: Research from activity perspectives (pp. 62-96). Fort Collins, CO/La Jolla, CA: The WAC Clearinghouse/Mind, Culture, and Activity. Retrieved from https://wac.colostate.edu/docs/books/selves_societies/selves_societies.pdf

Skelly, K., Rosenbaum, M., Barlow, P., \& Priebe, G. (2019). Comparing resident-patient encounters and case presentations in a family medicine clinic. Medical Education, 53(7), 677-686. https://doi.org/10.1111/medu.13806

Strauss, A., \& Corbin, J. (1998). Basics of qualitative research: Techniques and procedures for developing grounded theory (2nd ed.). Thousand Oaks, CA: Sage Publications, Inc.

Timmermans, S., \& Angell, A. (2001). Evidence-based medicine, clinical uncertainty, and learning to doctor. Journal of Health and Social Behavior, 42(4), 342-359.

Vygotsky, L. S. (1978). Mind in society: The development of higher psychological processes. Cambridge, MA: Harvard University Press.

Wang-Cheng, R. M., Barnas, G. P., Sigmann, P., Riendl, P. A., \& Young, M. J. (1989). Bedside case presentations: Why patients like them but learners don't. Journal of General Internal Medicine, 4(4), 284-287. https://doi.org/10.1007/bf02597397

Warmington, S. G. (2019). Storytelling encounters as medical education: Crafting relational identity. London: Routledge. https://doi.org/10.4324/9780429317262

Weinholz, D. (1983). Directing medical student clinical case presentations. Medical Education, 17(6), 364-368. https://doi.org/10.1111/j.1365-2923.1983.tb01121.x

MICHAEL GUEST has been teaching English for Medical Purposes (EMP) in Japan for over twenty years. He is the author of Conferencing and Presentation English for Young Academics (Springer, 2018), has written extensively on EMP and ESL for numerous academic journals, serves as an editor/reviewer for five journals, has performed over 300 workshops and conference presentations in 25 countries, is the coordinator of the East Asian Association of Medical English Teachers (EAMET), and was formerly a columnist on EFL affairs for the Daily Yomiuri/Japan News newspaper. He currently maintains a blog entitled 'Methods and Musings' with Language Teaching Professionals (LTP). 